\title{
Small Animal Veterinarians' Perceptions, Experiences, and Views of Common Dog Breeds, Dog Aggression, and Breed-Specific Laws in the United States
}

\author{
Lori R. Kogan ${ }^{1, *}$, Regina M. Schoenfeld-Tacher ${ }^{2}{ }^{\mathbb{D}}$, Peter W. Hellyer ${ }^{1}$, James A. Oxley ${ }^{3}{ }^{\mathbb{D}}$ and \\ Mark Rishniw ${ }^{4}$ \\ 1 Department of Clinical Sciences, College of Veterinary Medicine and Biomedical Sciences, \\ Colorado State University, Fort Collins, CO 80523, USA; Peter.Hellyer@ColoState.EDU \\ 2 Department of Molecular Biomedical Sciences, College of Veterinary Medicine, \\ North Carolina State University, Raleigh, NC 27607, USA; rmschoen@ncsu.edu \\ 3 Measham, 102 Bosworth Road, Measham, Swadlincote DE12 7Q, UK; james_oxley1@hotmail.com \\ 4 Veterinary Information Network, 777 W Covell Blvd, Davis, CA 95616, USA; mrishniw@vin.com \\ * Correspondence: lori.kogan@colostate.edu
}

Received: 23 September 2019; Accepted: 20 October 2019; Published: 23 October 2019

\begin{abstract}
Dog aggression directed towards humans is a common and serious behavioral and public health issue. This cross-sectional study was designed to gain insights into U.S. small animal veterinarians' views and experiences with the most common dog breeds in the U.S., dog aggression, and breed-specific legislation. An electronic survey was distributed via email to an online veterinary community, and responses were summarized and compared by means of $\chi^{2}$ and Cochran-Mantel-Haenszel tests. Most respondents were concerned about the risks of dog bite injuries, but the majority were not in favor of banning specific breeds of dogs in order to enhance public safety. When participants rated the perceived bite risk associated with popular dog breeds, Chow Chows were perceived as the highest risk, with pit bull types categorized as a moderate risk. Golden Retrievers were seen as the most appropriate for families with children. Public education about animal behavior was the most frequently endorsed policy intervention to increase public safety. These findings suggest that most veterinarians feel that banning an entire dog breed is not an effective way to ensure human safety. Instead, most respondents endorsed alternative initiatives, such as public education and stricter leash laws, to reduce the risk of dog bites.
\end{abstract}

Keywords: canine; bite; aggression; pit bull; breed; public health

\section{Introduction}

Dog ownership is common across the world, yet the United States has more dogs per person than any other country, with $38.4 \%$ of U.S. households owning a dog [1]. Dog ownership has been linked with improved physical and psychological health outcomes and overall wellbeing, but also zoonotic, injury, and bite risks [2-5]. Human directed dog aggression is a common and serious public health issue with a multi-factorial etiology [6-9]. Dog bites in the U.S. are one of the top categories of nonfatal injuries for children aged 5-9 years [10] with even higher numbers in developing regions of the world [4]. Including children and adults, there are an estimated $108 \mathrm{dog}$ bites per 100,000 people in the U.S. [11], with much more unreported [12].

In response to this public health risk, many countries and U.S. cities have introduced breed-specific legislation (e.g., the banning or restriction of specific breeds) [13-20]. The pit bull (actually consisting, in the U.S., of three separate breeds-American Staffordshire Terrier, Staffordshire Bull Terrier, and 
American Pit Bull Terrier) is a commonly banned breed. Specific banned breeds vary by country and U.S. states and cities [21-23]. Given the prevalence of breed-specific legislation, there is a surprising lack of evidence to support its efficacy. This is partially due to the large numbers of mixed breed dogs; estimated in the U.S. to be $51 \%$ of all dogs. In most cases, identification of mixed breed dogs is based on physical appearance, creating the potential for misidentification or generalization when bites occur [24,25]. As noted by Scott and Fuller [26], physical appearance is a poor indicator of breed or behavior when dealing with mixed breed dogs. Several studies investigating bite reports have reported similar inaccuracies, regardless of the level of prior knowledge of the person performing the identification. Members of the general public, animal shelter workers, law enforcement officers, and human health care professionals have all been shown to make incorrect breed determinations [27-33]. The media also plays a role in shaping the public opinion in relation to specific breeds, yet media reports are often inaccurate and subjective [34-36]. Podberscek [37], for example, reviewed UK newspaper articles both before and after the implementation of the UK Dangerous Dogs Act of 1991 and suggested that the media could negatively influence the public perception of specific dog breeds without adequate, accurate information. These inaccuracies are part of the reason why the CDC (Centers for Disease Control and Prevention), in 1998, stopped collecting breed data in dog-attack fatalities [13].

Even though there is increasing evidence that suggests that breed bans do not decrease dog bites, more countries and communities are passing breed ban legislation. In Ireland, for example, the percent of dog bites requiring hospitalization has increased by $21 \%$ (adjusted for population growth) since implementing the restrictions of 13 breeds in 1998 [38]. Studies in Toronto and Ontario, Canada, fail to show positive results from pit bull breed bans [39]. Many professional organizations, such as the British Veterinary Association, The Federation of Veterinarians of Europe, New Zealand Veterinary Association and American Veterinary Medical Association have taken a public stance against breed-specific legislation [40-42], in part due to the growing evidence that suggests that breed ban legislation has negative implications for dog welfare $[15,43,44]$. This has led countries such as the Netherlands to lift their breed ban because it was deemed ineffective [13].

Notwithstanding the existing research on dog aggression and breed-specific legislation, there has been little research conducted on veterinarians' perceptions of these topics. Therefore, the objective of this study was to gain insights into US small animal veterinarians' views and experiences with the most common dog breeds in the US, dog aggression, and breed-specific legislation.

\section{Materials and Methods}

In collaboration with VIN (Veterinary Information Network-an online veterinary community), an anonymous online survey was created to evaluate veterinarians' views regarding common dog breeds. This survey was administered directly through the VIN data collection portal. The survey was created and tested by researchers at Colorado State University and VIN. As part of this development, a pilot test in which the survey was distributed to a small sample of VIN members ( 10) was conducted to screen for question flow, appropriate branching, ambiguous questions, and survey errors. Feedback from the pilot test was analyzed and incorporated into the final version of the survey. A link to the survey was distributed via an email invitation to all VIN members ( $\mathrm{n}$ 35,000), and access was made available from 18 June 2018-14 August 2018. A follow-up message was sent two weeks after the initial invitation. Only data from respondents who stated they currently practice veterinary medicine as a small animal practitioner in the U.S. were included in the study. This was an anonymous survey; therefore, written informed consent was not required; instead, an introductory statement included an explanation of the study and the fact that potential participants were giving implied consent by completing the survey. The study was categorized as exempt by the Colorado State University's Institutional Review Board.

\section{Questionnaire Design}

The questionnaire consisted of nine sections, beginning with an introduction that explained the purpose of the study. This was followed by a section gathering respondents' demographic information 
(age, gender, and number of children). The second section asked about current dog ownership, breed bans within the respondent's locality, and their consideration of a pit bull breed dog as a pet.

Section three presented questions relating to whether the respondent was currently a practicing veterinarian, veterinary practice type (e.g., private, not for profit), main practice type (e.g., small animal, large animal, animal shelter, or feline-only), their number of years in veterinary practice, and their experiences with pit bull dogs inside and outside of the veterinary practice.

The fourth section included 18 statements and asked participants to indicate their level of agreement (i.e., strongly disagree, disagree, neither agree/disagree, agree, strongly agree), with each statement. These questions pertained to general dog ownership (e.g., "an adult should be able to own any breed of dog"); veterinarians involvement in the breed ban legislation (e.g., "veterinarians should support breed ban legislation in their local communities"); banning breeds and authority involvement (e.g., "banning certain breeds of dog by a government entity (city, county, state) is an overreach of governmental authority"); and perceptions of banned breed ownership and public safety (e.g., "banning specific breeds improves public safety").

The next section included three questions related to a list of twenty-three dog breeds. These breeds, with the exception of pit bull, were selected to reflect the most common dog breeds, according to the American Kennel Association, in the U.S. [45]. Pit bull was included in the list, even though it is not an actual breed, because of the common use of the term. The first question asked respondents to rate each breed in terms of serious bite risk from 'minimal', 'moderate', 'high risk', or 'don't know'. A further two questions asked participants if they feel some breeds should be banned and an open-ended question asking them to explain the reason for their answer. The next question asked participants to "Picture you are out for a walk and the following adult dog off-leash runs up to you. Please indicate your immediate emotional response" for a list of 23 common breeds. The possible answers ranged from $0=$ petrified to $10=$ deliriously happy/excited. The following question asked participants to indicate whether they thought each dog breed was appropriate for families with children under the age of 18. The last section asked about participants' endorsement to several dog-related laws that might affect public safety (e.g., "Stricter leash laws", "Mandatory muzzling of specific breeds when in public").

Statistical analysis, including descriptive statistics, Chi-square, and Cochran-Mantel-Haenszel test $(\mathrm{CMH})$, was conducted with a commercially available statistical software program (SPSS, Version 25; IBM Corp, Armonk, NY, USA). The CMH was used to test the association between gender and outcomes to the agreement level statements (agree or disagree) while taking into account the stratification of child status and pit bull ownership. The agreement statements were recoded into binary statements whereby 'strongly agree' and 'agree' were combined into 'agree' and 'neutral', 'disagree' and 'strongly disagree' were recoded into 'disagree'. CMH is used in observational studies to measure confounding variables when random assignment is not possible [46]. Due to the number of analyses conducted, the significance level $(\alpha)$ was set at a more conservative level of $p=0.01$. Not all survey questions received responses; therefore, the number corresponding to each particular question is indicated in the text and the tables.

\section{Results}

A total of 1961 surveys were completed by U.S. veterinarians providing care to small animals. This sample consisted of primarily small animal practitioners $(n=1637,83.5 \%)$, but also included others who work in small animal/exotic practices $(n=137,7.0 \%)$, mixed animal practices $(n=54,2.8 \%)$, and those working in animal shelters ( $n=29,1.5 \%$ ); (other or not applicable (NA), $n=104,5.3 \%$ ). When asked how long they have been in practice $(n=1939)$, the mean was 17.5 years (SD 12.6) with a median of 16 years.

The respondents included $1497(76.3 \%)$ females and $439(22.4 \%)$ males, while $25(1.3 \%)$ respondents chose other or NA. The number of respondents $(n=1961)$ who reported having children was 947 $(48.3 \%)$ with $1014(51.7 \%)$ reporting no children. The percent of females with children $(n=631 ; 42.2 \%)$ and the percent of males with children $(n=306 ; 69.7 \%)$ was statistically different $\left(\chi^{2}=103.19, d f=1\right.$, 
$p<0.001)$. The respondents' age $(n=1950)$ included $204(10.5 \%)$ under 30 years of age, $509(26.1 \%)$ whose ages were $30-39,433(22.2 \%)$ whose ages were $40-49,452(23.2 \%)$ whose ages were $50-59$, and $352(18.1 \%)$ whose ages were 60 or older.

The sample consisted of 1625 (82.9\%) current dog owners and 336 (17.2\%) participants who did not own a dog at the time of the survey. Among the dog owners who answered a question about their dog's breed $(n=1618), 348(21.5 \%)$ reported owning a pit bull-type dog, and $1270(78.5 \%)$ reported owning a breed other than a pit bull. The percent of females owning pit bulls ( $n=290 ; 23.2 \%$ ) and males owning pit bulls $(n=53 ; 15.1 \%)$ was statistically different $\left(\chi^{2}=10.58, d f=1, p=0.001\right)$. The participants who reported owning a dog, but not a pit bull, were asked if they would consider a pit bull as a pet $(n=1270)$, to which $837(65.9 \%)$ said yes and $433(34.1 \%)$ said no.

When asked about their experiences with pit bulls, only two (out of 1929) people reported not ever having had any direct interactions with pit bull dogs at work. The majority of participants, when asked about their experiences with pit bull dogs at work $(n=1925)$, reported these experiences as positive: very positive $(643,33.4 \%)$, positive $(930,48.3 \%)$, neutral $(304,15.8 \%)$, negative $(44,2.3 \%)$ and very negative $(4,0.2 \%)$. When asked about their experiences with pit bulls outside of work $(n=1957)$, 1792 (91.6\%) reported having at least some experience with pit bulls outside of work, with only (137, $7.0 \%)$ reporting no experience, and $(28,1.4 \%)$ said they did not remember). When asked about these experiences $(n=1792)$, most reported very positive $(487,27.2 \%)$ or positive $(860,48.0 \%)$, with fewer reporting neutral $(338,18.9 \%)$, negative $(81,4.5 \%)$, or very negative $(26,1.5 \%)$.

\subsection{Dog Aggression}

Participants were next asked four questions about dog aggression (Table 1). The majority of respondents reporting feeling that dog bites are a serious public health issue $(81.1 \%)$, and that dog aggression against other dogs is a serious community/societal problem (78.0\%). Most also agreed that owners of aggressive/dangerous dogs should be held legally accountable if their dog attacks/bites another dog (95.2\%) or a person (97.2\%). The Cochran-Mantel-Haenszel test was used to assess differences in responses to the aggression questions based on gender, controlling for child status, and pit bull ownership, and no differences were found between men and women for any of the four dog aggression questions.

Table 1. Dog aggression statements.

\begin{tabular}{|c|c|c|}
\hline Statements & $\begin{array}{l}\text { Agree } \\
n(\%)\end{array}$ & $\begin{array}{c}\text { Disagree } \\
n(\%)\end{array}$ \\
\hline $\begin{array}{l}\text { Dog aggression against other dogs is a serious community/societal } \\
\text { problem }(n=1952)\end{array}$ & $1523(78.0 \%)$ & $429(22.0 \%)$ \\
\hline Dog bites are a serious public health issue $(n=1947)$ & $1579(81.1 \%)$ & $368(18.9 \%)$ \\
\hline $\begin{array}{l}\text { Owners of aggressive/dangerous dogs should be held legally } \\
\text { accountable if their dog attacks/bites another dog }(n=1950)\end{array}$ & $1856(95.2 \%)$ & $94(4.8 \%)$ \\
\hline $\begin{array}{l}\text { Owners of aggressive/dangerous dogs should be held legally } \\
\text { accountable if their dog attacks a person }(n=1946)\end{array}$ & $1892(97.2 \%)$ & $54(2.8 \%)$ \\
\hline
\end{tabular}

\subsection{Breed Characteristics}

The next four questions pertained to breed characteristics (Table 2). The majority of respondents reported feeling that some breeds of dogs are more likely to be aggressive towards other dogs $(70.1 \%)$ or people $(65.0 \%)$ than other breeds and that certain breeds of dogs are better suited to working with trained handlers (e.g., in law enforcement or the military) than as family pets $(57.5 \%)$. Yet, most respondents $(65.4 \%)$ agreed that "Depending on the circumstances, all breeds of dogs are equally likely to bite a person".

When asked if "some breeds of dogs are more likely to be aggressive towards other dogs than other breeds", males and females with children and no pit bull differed in agreement level $\left(\chi^{2}=10.57\right.$; 
df $1, p<0.001) ; 197(87.6 \%)$ males agreed compared to $342(77.0 \%)$ females. The same results were found for the question "Some breeds of dogs are more likely to be aggressive towards people than other breeds" whereby there was a gender difference for those with children and no pit bull $\left(\chi^{2}=9.76\right.$; $d f 1, p=0.002) ; 188(83.6 \%)$ males agreed compared to $322(72.7 \%)$ females. Similarly, the question "Depending on the circumstances, all breeds of dogs are equally likely to bite a person", there was a difference between men and women with children and no pit bull (Pearson $\chi^{2}=17.36 ; d f 1, p<0.001$ ); $100(44.2 \%)$ males agreed compared to $271(61.2 \%)$ females. No differences in the agreement level were found for the statement, "Certain breeds of dogs are better suited to working with trained handlers (e.g., in law enforcement or the military) than as family pets".

Table 2. Perceived association between dog breed and behavior.

\begin{tabular}{ccc}
\hline Statements & $\begin{array}{c}\text { Agree } \\
\boldsymbol{n} \mathbf{( \% )}\end{array}$ & $\begin{array}{c}\text { Disagree } \\
\boldsymbol{n} \mathbf{( \% )}\end{array}$ \\
\hline $\begin{array}{c}\text { Certain breeds of dogs are better suited to working with trained } \\
\text { handlers (e.g., in law enforcement or the military) than as family } \\
\text { pets }(n=1948)\end{array}$ & $1120(57.5 \%)$ & $828(42.5 \%)$ \\
$\begin{array}{c}\text { Some breeds of dogs are more likely to be aggressive towards other } \\
\text { dogs than other breeds }(n=1952)\end{array}$ & $1369(70.1 \%)$ & $583(29.9 \%)$ \\
$\begin{array}{c}\text { Some breeds of dogs are more likely to be aggressive towards } \\
\text { people than other breeds }(n=1954)\end{array}$ & $1271(65.0 \%)$ & $683(35.0 \%)$ \\
$\begin{array}{c}\text { Depending on the circumstances, all breeds of dogs are equally } \\
\text { likely to bite a person }(n=1953)\end{array}$ & $1278(65.4 \%)$ & $675(34.6 \%)$ \\
\hline
\end{tabular}

\subsection{Breed Banning}

Participants were next asked their views about specific breed banning (Table 3). Overall, participants were opposed to breed bans. The majority (75.3\%) agreed that banning specific breeds creates an animal welfare issue and that banning certain breeds of dogs by a government entity (city, county, state) is an overreach of governmental authority (76.2\%). Most disagreed that particular dog breeds should be banned from being around children (87.8\%) or that banning specific breeds of dogs improves public safety $(89.2 \%)$.

Significant gender differences in the agreement level to the statement, "Banning specific breeds creates an animal welfare issue" for participants with children and no pit bull were found (Pearson $\left.\chi^{2}=18.50 ; d f 1, p<0.001\right) ; 124(55.6 \%)$ males agreed compared to $318(72.3 \%)$ females. Gender also made a difference for those with no children and did own a pit bull (Pearson $\chi^{2}=11.05 ; d f 1, p=0.004$ ); $22(78.6 \%)$ males agreed compared to $180(94.2 \%)$ females in agreement level to the statement "Banning certain breeds of dogs by a government entity (city, county, state) is an overreach of governmental authority". When asked if "Some dog breeds should be banned from being around children", gender differences were found for those with or without children who did not own a pit bull. For those with children, 60 (26.9\%) males agreed compared to $56(12.6 \%)$ females. (Pearson $\chi^{2}=20.98$; $d f 1, p<0.001$ ). For those without children, $14(19.7 \%)$ males agreed compared to $38(7.4 \%)$ females (Pearson $\chi^{2}=11.61$; df $1, p=0.001)$. Lastly, gender made a difference for those with children who did not own a pit bull when asked if "Banning specific breeds of dogs improves public safety", whereby 52 (23.1\%) males agreed compared to $52(11.8 \%)$ females (Pearson $\chi^{2}=14.59$; df $\left.1, p<0.001\right)$. 
Table 3. Perceptions of breed ban legislation.

\begin{tabular}{ccc}
\hline Statements & $\begin{array}{c}\text { Agree } \\
\boldsymbol{n} \mathbf{( \% )}\end{array}$ & $\begin{array}{c}\text { Disagree } \\
\boldsymbol{n}(\mathbf{\%})\end{array}$ \\
\hline Banning specific breeds creates an animal welfare issue $(n=1945)$ & $1464(75.3 \%)$ & $481(24.7 \%)$ \\
Banning certain breeds of dogs by a government entity (city, county, state) & $1486(76.2 \%)$ & $465(23.8 \%)$ \\
is an overreach of governmental authority $(n=1951)$ & $237(12.2 \%)$ & $1712(87.8 \%)$ \\
Some dog breeds should be banned from being around children $(n=1949)$ & $210(10.8 \%)$ & $1735(89.2 \%)$ \\
\hline Banning specific breeds of dogs improves public safety $(n=1945)$ & &
\end{tabular}

\subsection{Pet Ownership}

The next three questions pertained to pet and specifically dog ownership in general (Table 4). The vast majority of participants agreed that "Socially irresponsible pet ownership is a significant societal problem" (95.1\%). When asked if "owning a dog is a right rather than a privilege", the majority disagreed $(81.3 \%)$. Opinions were mixed, however, on whether "any adult should be able to own any breed of dog", $44.3 \%$ agreed while $55.7 \%$ disagreed.

When asked if "Owning a dog is a right rather than a privilege", gender made a difference for those with children who did not own a pit bull: $62(27.6 \%)$ males agreed compared to 68 (15.3\%) females (Pearson $\chi^{2}=14.18$; $d f 1, p<0.001$ ). No agreement level differences were found for the statements "Socially irresponsible pet ownership is a significant societal problem" or "Any adult should be able to own any breed of dog".

Table 4. Perceptions of pet ownership in the context of society.

\begin{tabular}{ccc}
\hline Statements & $\begin{array}{c}\text { Agree } \\
\boldsymbol{n} \mathbf{( \% )}\end{array}$ & $\begin{array}{c}\text { Disagree } \\
\boldsymbol{n} \mathbf{( \% )}\end{array}$ \\
\hline Socially irresponsible pet ownership is a significant societal problem $(n=1953)$ & $1857(95.1 \%)$ & $96(4.9 \%)$ \\
Any adult should be able to own any breed of dog $(n=1947)$ & $862(44.3 \%)$ & $1085(55.7 \%)$ \\
Owning a dog is a right rather than a privilege $(n=1952)$ & $366(18.2 \%)$ & $1586(81.3 \%)$ \\
\hline
\end{tabular}

\subsection{Veterinarians' Role}

Veterinarians' role as it relates to aggressive dogs and breed bans constituted the subject of the next three questions (Table 5). Most participants reported feeling that veterinarians have a role in advising clients on how to train/manage aggressive/dangerous dogs (86.3\%). They did not feel that veterinarians should support breed ban legislation in their local communities $(81.8 \%)$, and in fact, most $(66.1 \%)$ felt that veterinarians openly supporting any type of breed ban negatively affects the public perception of veterinarians.

There was a difference between agreement level of males and females with both children and a pit bull to the statement "Veterinarians have a role in advising clients on how to train/manage aggressive/dangerous dogs", where 16 (64.0\%) males agreed to the statement compared to $88(90.7 \%)$ females (Pearson $\chi^{2}=11.29$; $d f 1, p=0.001$ ).

There was also a difference in agreement level between males and females with children, but no pit bulls to the statement, "Veterinarians should support breed ban legislation in their local communities" $26(11.6 \%)$ males agreed compared to $18(4.1 \%)$ females (Pearson $\left.\chi^{2}=13.74 d f 1, p<0.001\right)$ ). Similarly, there was a difference between males and females with children but no pit bull to agreement with the sentiment "I feel it negatively affects the public perception of a veterinarian to openly support any type of breed ban"; 119 (52.9\%) males agreed compared to 287 (65.1\%) females (Pearson $\chi^{2}=9.30 ; d f 1$, $p=0.002)$. 
Table 5. Perceptions of veterinary involvement with breed bans.

\begin{tabular}{ccc}
\hline Statements & $\begin{array}{c}\text { Agree } \\
\boldsymbol{n} \mathbf{( \% )}\end{array}$ & $\begin{array}{c}\text { Disagree } \\
\boldsymbol{n} \mathbf{( \% )}\end{array}$ \\
\hline $\begin{array}{c}\text { Veterinarians have a role in advising clients in how to train/manage } \\
\text { aggressive/dangerous dogs }(n=1949)\end{array}$ & $1682(86.3 \%)$ & $267(13.7 \%)$ \\
$\begin{array}{c}\text { Veterinarians should support breed ban legislation in their local } \\
\text { communities }(n=1950)\end{array}$ & $87(4.5 \%)$ & $1863(95.5 \%)$ \\
$\begin{array}{c}\text { I feel it negatively affects the public perception of a veterinarian to openly } \\
\text { support any type of breed ban }(n=1947)\end{array}$ & $1287(66.1 \%)$ & $660(33.9 \%)$ \\
\hline
\end{tabular}

\subsection{Serious Bite Risk Based on Breed}

Participants were presented with a list of common breeds and asked to indicate their perception of the different breeds' serious bite risk (defined as requiring medical treatment) as minimal, moderate, or high (or don't know). These breeds are listed in Table 6, in order of perceived severity of the risk. The breeds felt to pose the highest risk of serious bites include Chow Chows (perceived as high risk by $60.6 \%$ ), followed by Chihuahuas (perceived as high risk by $48.5 \%$ ), German shepherds (47.3\%), Rottweilers (44.2\%), Akitas (41.8\%), and Belgian Malinois (39.7\%). The dog breeds with the lowest perceived risk of serious bites include Golden retriever (4.6\%), Labrador retriever (4.6\%), English bulldog (4.1\%), Standard poodle (3.6\%), and Beagles (2.3\%) had the lowest perceived risk.

Table 6. Veterinarians' perceptions of serious bite risk of 23 common U.S. dog breeds.

\begin{tabular}{ccccc}
\hline Breed & $\begin{array}{c}\text { High } \\
\boldsymbol{n} \mathbf{( \% )}\end{array}$ & $\begin{array}{c}\text { Moderate } \\
\boldsymbol{n} \mathbf{( \% )}\end{array}$ & $\begin{array}{c}\text { Minimal } \\
\boldsymbol{n} \mathbf{( \% )}\end{array}$ & $\begin{array}{c}\text { Don't know } \\
\boldsymbol{n} \mathbf{( \% )}\end{array}$ \\
\hline High risk (> 39\%) & & & \\
Chow Chow $(n=1947)$ & $1179(60.6 \%)$ & $639(32.8 \%)$ & $66(3.4 \%)$ & $63(3.2 \%)$ \\
Chihuahua $(n=1945)$ & $944(48.5 \%)$ & $699(35.9 \%)$ & $252(13.0 \%)$ & $50(2.6 \%)$ \\
German shepherd $(n=1944)$ & $920(47.3 \%)$ & $816(42.0 \%)$ & $148(7.6 \%)$ & $60(3.1 \%)$ \\
Rottweiler $(n=1937)$ & $856(44.2 \%)$ & $827(42.7 \%)$ & $185(9.6 \%)$ & $69(3.6 \%)$ \\
Akita $(n=1943)$ & $813(41.8 \%)$ & $879(45.2 \%)$ & $144(7.4 \%)$ & $107(5.5 \%)$ \\
Belgian Malinois $(n=1944)$ & $772(39.7 \%)$ & $819(42.1 \%)$ & $211(10.9 \%)$ & $142(7.3 \%)$ \\
\hline Moderate risk & & & & \\
Siberian husky $(n=1936)$ & $508(26.2 \%)$ & $959(49.5 \%)$ & $407(21.0 \%)$ & $62(3.2 \%)$ \\
Dalmatian $(n=1943)$ & $459(23.6 \%)$ & $988(50.8 \%)$ & $368(18.9 \%)$ & $128(6.6 \%)$ \\
Pit bull type $(n=1938)$ & $427(22.0 \%)$ & $964(49.7 \%)$ & $481(24.8 \%)$ & $66(3.4 \%)$ \\
Mastiff $(n=1936)$ & $350(18.1 \%)$ & $809(41.8 \%)$ & $701(36.2 \%)$ & $76(3.9 \%)$ \\
Dachshund $(n=1944)$ & $346(17.8 \%)$ & $1030(53.0 \%)$ & $515(26.5 \%)$ & $53(2.7 \%)$ \\
Cocker spaniel $(n=1944)$ & $307(15.8 \%)$ & $1050(54.0 \%)$ & $526(27.1 \%)$ & $61(3.1 \%)$ \\
Jack Russell Terrier $(n=1940)$ & $305(15.7 \%)$ & $1050(54.1 \%)$ & $527(27.2 \%)$ & $58(3.0 \%)$ \\
Great Dane $(n=1945)$ & $298(15.3 \%)$ & $810(41.6 \%)$ & $773(39.7 \%)$ & $64(3.3 \%)$ \\
American bulldog $(n=1942)$ & $258(13.3 \%)$ & $860(44.3 \%)$ & $745(38.4 \%)$ & $79(41 \%)$ \\
Doberman pinscher $(n=1944)$ & $222(11.4 \%)$ & $839(43.2 \%)$ & $820(42.2 \%)$ & $63(3.2 \%)$ \\
\hline Low risk & & & & \\
Yorkshire terrier $(n=1935)$ & $136(7.0 \%)$ & $684(35.3 \%)$ & $1056(54.6 \%)$ & $59(3.0 \%)$ \\
Boxer $(n=1940)$ & $104(5.4 \%)$ & $727(37.5 \%)$ & $1043(53.8 \%)$ & $66(3.4 \%)$ \\
Golden retriever $(n=1943)$ & $90(4.6 \%)$ & $403(20.7 \%)$ & $1393(71.7 \%)$ & $57(2.9 \%)$ \\
Labrador retriever $(n=1938)$ & $90(4.6 \%)$ & $473(24.4 \%)$ & $1316(67.9 \%)$ & $59(3.0 \%)$ \\
English bulldog $(n=1944)$ & $80(4.1 \%)$ & $609(31.3 \%)$ & $1193(61.4 \%)$ & $62(3.2 \%)$ \\
Standard poodle $(n=1937)$ & $69(3.6 \%)$ & $449(23.2 \%)$ & $1354(69.9 \%)$ & $65(3.4 \%)$ \\
Beagle $(n=1939)$ & $44(2.3 \%)$ & $573(29.6 \%)$ & $1253(64.6 \%)$ & $69(3.6 \%)$ \\
\hline
\end{tabular}

\subsection{Appropriate Breeds for Families with Children}

Participants were asked how suitable they felt a list of common U.S. dog breeds are for families with children under the age of 18 with possible responses, including appropriate, neutral, inappropriate, 
and don't know. These results are listed in order of decreasing level of appropriateness in Table 7. The breeds felt to be most appropriate for families with children include Golden retrievers (rated as appropriate by 76.9\%), Labrador retrievers (75.7\%), Beagles (67.7\%), Standard poodles (62.7\%), and Boxers (58.5\%). The breeds felt to be the least appropriate include Chow Chows (10.3\%), Akitas (10.4\%), Belgian Malinois (12.2\%), and Rottweilers (17.0\%).

Table 7. Veterinarians' views on the appropriateness of ownership for families with children under the age of 18 of 23 common U.S. dog breeds.

\begin{tabular}{ccccc}
\hline Breed & $\begin{array}{c}\text { Appropriate } \\
\boldsymbol{n} \mathbf{( \% )}\end{array}$ & $\begin{array}{c}\text { Neutral } \\
\boldsymbol{n} \mathbf{( \% )}\end{array}$ & $\begin{array}{c}\text { Inappropriate } \\
\boldsymbol{n} \mathbf{( \% )}\end{array}$ & $\begin{array}{c}\text { Don't know } \\
\boldsymbol{n} \mathbf{( \% )}\end{array}$ \\
\hline Golden retriever $(n=1931)$ & $1485(76.9 \%)$ & $390(20.2 \%)$ & $6(0.3 \%)$ & $50(2.6 \%)$ \\
Labrador retriever $(n=1929)$ & $1461(75.7 \%)$ & $410(21.3 \%)$ & $7(0.4 \%)$ & $51(2.6 \%)$ \\
Beagle $(n=1933)$ & $1309(67.7 \%)$ & $54(29.2 \%)$ & $16(0.8 \%)$ & $44(2.3 \%)$ \\
Standard poodle $(n=1928)$ & $1208(62.7 \%)$ & $654(33.9 \%)$ & $14(0.7 \%)$ & $52(2.7 \%)$ \\
Boxer $(n=1934)$ & $1132(58.5 \%)$ & $714(36.9 \%)$ & $42(2.2 \%)$ & $46(2.4 \%)$ \\
English bulldog $(n=1931)$ & $880(45.6 \%)$ & $897(46.5 \%)$ & $101(5.2 \%)$ & $53(2.7 \%)$ \\
Yorkshire terrier $(n=1933)$ & $876(45.3 \%)$ & $842(43.6 \%)$ & $166(8.6 \%)$ & $49(2.5 \%)$ \\
Dachshund $(n=1934)$ & $721(37.4 \%)$ & $952(49.2 \%)$ & $216(11.2 \%)$ & $45(2.3 \%)$ \\
Doberman pinscher $(n=1932)$ & $689(35.7 \%)$ & $1012(52.4 \%)$ & $175(9.1 \%)$ & $56(2.9 \%)$ \\
Cocker spaniel $(n=1934)$ & $678(35.1 \%)$ & $1018(53.2 \%)$ & $178(9.2 \%)$ & $50(2.6 \%)$ \\
Great Dane $(n=1932)$ & $663(34.3 \%)$ & $977(50.6 \%)$ & $242(12.5 \%)$ & $50(2.6 \%)$ \\
American bulldog $(n=1930)$ & $638(33.1 \%)$ & $984(51.0 \%)$ & $250(13.0 \%)$ & $58(3.0 \%)$ \\
Jack Russell terrier $(n=1931)$ & $634(32.8 \%)$ & $1027(53.2 \%)$ & $219(11.3 \%)$ & $51(2.6 \%)$ \\
Pit bull type $(n=1933)$ & $634(32.8 \%)$ & $898(46.5 \%)$ & $352(18.2 \%)$ & $49(2.5 \%)$ \\
Mastiff $(n=1933)$ & $554(28.7 \%)$ & $993(51.4 \%)$ & $319(16.5 \%)$ & $67(3.5 \%)$ \\
Chihuahua $(n=1936)$ & $437(22.6 \%)$ & $937(48.4 \%)$ & $515(26.6 \%)$ & $47(2.4 \%)$ \\
Dalmatian $(n=1932)$ & $412(21.3 \%)$ & $1065(55.1 \%)$ & $373(19.3 \%)$ & $82(4.2 \%)$ \\
German shepherd $(n=1934)$ & $409(21.1 \%)$ & $1007(52.1 \%)$ & $470(24.3 \%)$ & $48(2.5 \%)$ \\
Siberian husky $(n=1932)$ & $364(18.8 \%)$ & $1049(54.3 \%)$ & $467(24.2 \%)$ & $52(2.7 \%)$ \\
Rottweiler $(n=1930)$ & $328(17.0 \%)$ & $901(46.7 \%)$ & $648(33.6 \%)$ & $53(2.7 \%)$ \\
Belgian Malinois $(n=1935)$ & $237(12.2 \%)$ & $835(43.2 \%)$ & $733(37.9 \%)$ & $130(6.7 \%)$ \\
Akita $(n=1961)$ & $200(10.4 \%)$ & $795(41.2 \%)$ & $821(42.5 \%)$ & $114(5.9 \%)$ \\
Chow Chow $(n=1935)$ & $199(10.3 \%)$ & $730(37.7 \%)$ & $945(48.8 \%)$ & $61(3.2 \%)$ \\
\hline
\end{tabular}

\subsection{Reaction to Unfamiliar Dogs Off-Leash}

Participants were asked to imagine that they were out for a walk, and an adult dog, off-leash, runs up to them. They were asked to report their immediate emotional response on a scale from 0-10, with $0=$ petrified and $10=$ deliriously happy/excited. The mean, median, and mode scores for each breed are listed in Table 8. The breeds that were reported to elicit the most fearful/negative response were Chow Chows, Rottweilers, Akitas, German shepherds, and Belgian Malinois. Participants reported they would feel the happiest or most excited by Golden retrievers, Labrador retrievers, Beagles, and Standard poodles. 
Table 8. Mean, median, and mode scores given by veterinarians to rate their emotional response to being approached by an unfamiliar adult dog off-leash from a list of 23 common U.S. dog breeds. $(0=$ petrified and $10=$ deliriously happy/excited $)$.

\begin{tabular}{|c|c|c|c|c|}
\hline Breed $(n)$ & Mean & $\begin{array}{l}\text { Standard } \\
\text { Deviation }\end{array}$ & Median & Mode \\
\hline Chow Chow $(n=1619)$ & 2.85 & 1.79 & 3 & 3 \\
\hline Rottweiler $(n=1592)$ & 3.07 & 2.13 & 3 & 4 \\
\hline Akita $(n=1535)$ & 3.14 & 1.77 & 3 & 3 \\
\hline German shepherd $(n=1577)$ & 3.18 & 2.11 & 3 & 4 \\
\hline Belgian Malinois $(n=1528)$ & 3.27 & 1.93 & 3 & 4 \\
\hline Siberian Husky $(n=1392)$ & 3.93 & 2.00 & 4 & 4 \\
\hline Dalmatian $(n=1301)$ & 4.23 & 1.89 & 4 & 4 \\
\hline Pit bull type $(n=1492)$ & 4.31 & 2.62 & 4 & 4 \\
\hline Mastiff $(n=1438)$ & 4.36 & 2.39 & 4 & 4 \\
\hline Doberman pinscher $(n=1410)$ & 4.54 & 2.17 & 4 & 4 \\
\hline Chihuahua $(n=1294)$ & 4.58 & 2.13 & 4 & 4 \\
\hline American bulldog $(n=1334)$ & 4.67 & 2.30 & 4 & 4 \\
\hline Great Dane $(n=1444)$ & 4.80 & 2.45 & 4 & 4 \\
\hline Jack Russell terrier $(n=1241)$ & 5.03 & 1.96 & 5 & 4 \\
\hline Cocker spaniel $(n=1196)$ & 5.18 & 1.91 & 5 & 4 \\
\hline Dachshund $(n=1235)$ & 5.47 & 1.95 & 5 & 6 \\
\hline Boxer $(n=1312)$ & 5.84 & 2.21 & 6 & 6 \\
\hline English bulldog $(n=1232)$ & 6.02 & 2.11 & 6 & 6 \\
\hline Yorkshire terrier $(n=1196)$ & 6.17 & 2.04 & 6 & 6 \\
\hline Standard poodle $(n=1276)$ & 6.47 & 2.11 & 6 & 6 \\
\hline Beagle $(n=1235)$ & 6.52 & 1.90 & 6 & 6 \\
\hline Labrador retriever $(n=1420)$ & 7.05 & 2.11 & 7 & 7 \\
\hline Golden retriever $(n=1439)$ & 7.34 & 2.12 & 8 & 10 \\
\hline
\end{tabular}

Lastly, participants were asked to indicate their degree of endorsement of several policies communities have enacted in an effort to increase public safety $(n=1961)$. These statements are listed in order of decreasing endorsement rate in Table 9. The most commonly endorsed policies include public education about animal behavior (endorsed by $90.0 \%$ ), stricter leash laws $(79.9 \%)$, and public education about animal welfare $(78.4 \%)$.

Table 9. Veterinarians' reported endorsement of community policies enacted in efforts to increase public safety.

\begin{tabular}{cc}
\hline Policy & $\begin{array}{c}\text { Endorsement Rate } \\
\boldsymbol{n} \mathbf{( \% )}\end{array}$ \\
\hline Public education about animal behavior & $1764(90.0 \%)$ \\
Stricter leash laws & $1567(79.9 \%)$ \\
Public education about animal welfare & $1538(78.4 \%)$ \\
Harsher penalties for dog owners in the event of a dog bite or attack & $1419(72.4 \%)$ \\
Stricter laws about picking up dog waste & $1349(68.8 \%)$ \\
Stricter fencing or containment laws & $1261(64.3 \%)$ \\
Anti-chaining \& anti-tethering laws & $1178(60.1 \%)$ \\
Compulsory owner-dog training & $863(44.0 \%)$ \\
Mandatory spay/neuter for specific breeds & $384(19.6 \%)$ \\
Mandatory registration for specific breeds & $265(13.5 \%)$ \\
Mandatory muzzling of specific breeds when in public & $120(6.1 \%)$ \\
\hline
\end{tabular}

\section{Discussion}

Dog bites and dog aggression are serious public health concerns [47-51]. The aim of this study was to investigate U.S. veterinarians' experiences, perceptions, and views of dog breeds, dog aggression, breed-specific legislation. When there were significant differences in participants' responses based on 
their gender, controlling for parental status and pit bull ownership, males were more likely to report feeling that some breeds are more aggressive than other breeds and were more open to some aspects of breed-specific legislation. Further study is needed to explore these gender differences to better understand the relationship between gender and parental status on veterinarians' views on aggressive dogs, and pit bulls in particular.

Many of the breeds identified by this study's participants as high bite risk or inappropriate for families with young children have been named in other studies [52-57]. Yet, as Wake [58] notes, a corresponding increase in bite reports pertaining to a specific breed can follow an increase in popularity of that breed. In other words, when there are more dogs of a particular breed, this could potentially lead to an increase in reported bites by that breed, something that should be taken into consideration when attempting to collect data on breed aggression risks [58]. Although the results of this study suggest that veterinarians think some dog breeds pose a more serious bite risk than other breeds, the majority of respondents also reported feeling that, depending on the circumstances, all dog breeds are capable of biting; a sentiment echoed in numerous other papers $[6,59,60]$. Additional dog-specific factors such as sex and age, early experience, socialization and training, health (medical and behavioral), and reproductive status, as well as human factors, including the use of physical punishment, supervision, owner personality, and victim behavior have also been shown to influence aggressive behaviors [6,61-63].

Regardless of the breed, respondents overwhelmingly reported feeling that dog aggression (against both people and other dogs) is a serious public health concern and that owners of aggressive dogs should be held accountable. Importantly, participants echoed other study results in their sentiments that veterinarians should play an active role in advising clients about how to handle aggressive dogs $[64,65]$. Unfortunately, many veterinarians do not feel comfortable discussing aggressive behavior problems with clients [66]. For these reasons, it has been suggested that more animal behavior training is needed in veterinary curricula [66-68].

While participants acknowledge dog aggression as a serious public health concern, they do not feel that banning a specific breed is a viable solution. Some of the reasoning behind these views could be attributed to inherent problems with breed ban legislation, especially as it relates to pit bulls. As noted earlier, a central issue is that pit bull is not actually a breed, but instead a group of breeds [32]. The classification of 'pit bull' is typically based on a dogs' physical resemblance to one of several breeds that have been associated with the term pit bull [28,69], when, in fact, most people are unable to identify a pit bull accurately $[27,28,30,31]$.

Breed bans are often a reaction to horrific dog bite stories depicted in popular media $[37,70]$. Yet, the accuracy of bite reports and resultant media stories have been questioned [33]. In particular, pit bulls are often identified as problematic and dangerous [71], but in many medical reports, the breed of the offending dog is either not reported or assumed based on phenotypic characteristics [25]. In fact, one study [72] found that over one-half of dog-bite medical reports for children were missing breed information. This lack of data can lead to selection bias and compromised validity [72]. Another study found that approximately $51 \%$ of the dogs in the US are of mixed breed [73], yet the vast majority of dog bite reports include only one breed, giving the impression of a purebred [69]. Based on these studies and numerous others, it appears likely that many media reports on dog bites are misleading at best, or at worst, inaccurate. Unfortunately, however, these reports are the foundation for many dog bite and aggression studies. The CDC's report Dog Bite-Related Fatalities From 1979-1988, for example, relied on media stories in which breed identification was based on physical appearance [74]. These reports, therefore, often demonized pit bulls by perpetuating stereotypes or false information about the breed [75-77].

In addition to doubts about the effectiveness of breed bans, their impact on animal welfare is of growing concern. Several studies have suggested that these laws are ineffective. Additionally, they are expensive, difficult to implement, and subject responsible, law-abiding dog owners to unnecessary regulations/hardships. These breed bans also negatively impact dog welfare [15,38,43,78-80]. It is, therefore, encouraging to note that most veterinarians, arguably a powerful lobbying group, agree with 
the sentiment that banning an entire dog breed is not an effective way to ensure human safety [75]. The American Veterinary Medical Association (AVMA) succinctly stated the problem with breed-specific legislation, "While breed is a factor, the impact of other factors relating to the individual animal (such as training method, sex, and neutering status), the target (e.g., owner versus stranger), and the context in which the dog is kept (e.g., urban versus rural) prevent breed from having significant predictive value in its own right." [57] (p. 3).

Several studies suggest there are better solutions for dog bites and dog aggression, including better owner and public education about dog behavior and dog bite prevention, responsible ownership, and active enforcement of dog control ordinances-all of which were endorsed by the majority of participants [57,81]. Teaching adults and children how to understand dog signaling and behaviors, for example, has been found to be an effective strategy in increasing dog behavior knowledge and improving appropriate and safe behaviors of people around dogs $[4,82,83]$. In addition, to educate about dog behavior, there is a need for public education on pet care and welfare. Given the fact that most dog bites are from their own pet dog, educating families (e.g., children, adults, and elderly) about animal behavior has been seen as critical in reducing dog bites. Dissemination of this information could be done in a variety of ways by different community entities. Examples include information provided by veterinarians and animal-related companies (e.g., pet supplies) or distributed by city entities (e.g., utility companies, city/county news, etc.). Another consideration is the mandatory inclusion of training for owners who are ticketed or cited for a dog-related incident [84].

This study was not without limitations. The survey was distributed online, and respondents might not be representative of all small animal U.S. practitioners. The results should be interpreted with care and cannot be generalized to the general population for several reasons. First and foremost, it is not known if these views are shared by non-veterinarians. Additionally, this sample was predominately female and included a significant number of pit bull owners. The reasons for this are unclear. It is not known if veterinarians are more likely to own pit bulls, or if those that own pit bulls were more likely to complete this survey. These factors speak to the need for further study with the general population to assess potential differences of views and attitudes and warrant some caution when interpreting the data. In summary, veterinarians have a vested interest in a reduction of dog bite incidents within their communities. By increasing behavior training in veterinary curricula, and offering more behavior-related continuing education, it is the hope that veterinarians will feel more comfortable addressing animal aggression issues with their clients. In addition, community supported public education on dog behavior, enhanced licensure compliance, stricter leash laws, and penalties for negligent dog owners of aggressive dogs appear to be viable options to mitigate the risk of aggressive dogs that are supported by both veterinarians and current research.

Author Contributions: Please note the following authors' contributions: conceptualization: L.R.K., P.W.H., R.M.S.-T., J.A.O., M.R.; methodology: L.R.K., M.R.; formal analysis: L.R.K.; writing—original draft preparation: L.R.K, J.A.O.; writing-review and editing, L.R.K., P.W.H., R.M.S.-T., J.A.O., M.R.

Funding: This research received no external funding.

Conflicts of Interest: The authors declare no conflict of interest.

\section{References}

1. Filippo, M.S. AVMA releases latest stats on pet pwnership and veterinary care. July 2018. Available online: https:/www.avma.org/News/PressRoom/Pages/AVMA-releases-latest-stats-on-petownership-and-veterinary-care.aspx (accessed on 26 July 2019).

2. Oyama, M.A.; Citron, L.; Shults, J.; Cimino Brown, D.; Serpell, J.A.; Farrar, J.T. Measuring quality of life in owners of companion dogs: Development and validation of a dog owner-specific quality of life questionnaire. Anthrozoos 2017, 30, 61-75. [CrossRef]

3. Stull, J.W.; Stevenson, K.B. Zoonotic disease risks for immunocompromised and other high-risk clients and staff. Vet. Clin. N. Am. Small Anim. Pract. 2015, 45, 377-392. [CrossRef] [PubMed] 
4. Shen, J.; Rouse, J.; Godbole, M.; Wells, H.L.; Boppana, S.; Schwebel, D.C. Systematic review: Interventions to educate children about dog safety and prevent pediatric dog-bite injuries: A meta-analytic review. J. Pediatric Psychol. 2016, 42, 779-791. [CrossRef] [PubMed]

5. Willmott, H.; Greenheld, N.; Goddard, R. Beware of the dog? An observational study of dog-related musculoskeletal injury in the UK. Accid. Anal. Prev. 2012, 46, 52-54. [CrossRef]

6. Hsu, Y.; Sun, L. Factors associated with aggressive responses in pet dogs. Appl. Anim. Behav. Sci. 2010, 123, 108-123. [CrossRef]

7. Love, M.; Overall, K.L. How anticipating relationships between dogs and children can help prevent disasters. J. Am. Vet. Med. Assoc. 2001, 219, 446-453. [CrossRef]

8. Ramgopal, S.; Brungo, L.B.; Bykowski, M.R.; Pitetti, R.D.; Hickey, R.W. Dog bites in a U.S. county: Age, body part and breed in paediatric dog bites. Acta Pediatric 2018, 107, 893-899. [CrossRef]

9. Peters, V.; Sottiaux, M.; Appelboom, J.; Kahn, A. Posttraumatic stress disorder after dog bites in children. J. Pediatric 2004, 144, 121-122. [CrossRef]

10. Body, F. National estimates of the 10 leading causes of nonfatal injuries treated in hospital emergency departments-2017. Atlanta, GA, USA, 2018. Available online: https://www.cdc.gov/injury/wisqars/pdf/ /leading_causes_of_nonfatal_injury_2017-508.pdf (accessed on 30 July 2019).

11. Overall Dog Bite Nonfatal Emergency Department Visits and Rates Per 100,000; CDC: Atlanta, GA, USA, 2017. Available online: https://webappa.cdc.gov/sasweb/ncipc/nfirates.html (accessed on 30 July 2019).

12. Westgarth, C.; Brooke, M.; Christley, R.M. How many people have been bitten by dogs? A cross-sectional survey of prevalence, incidence and factors associated with dog bites in a UK community. J. Epidemiol. Community Health 2018, 72, 331-336. [CrossRef]

13. Nolen, S. The Dangerous Dog Debate. July 2017. Available online: https://www.avma.org/news/javmanews/ pages/171115a.aspx (accessed on 26 July 2019).

14. Walden, C.A. Overview of Breed Specific Legislation (bsl) Ordinances. Animal Legal \& Historical Center. Available online: https:/www.animallaw.info/article/overview-breed-specific-legislation-bsl-ordinances (accessed on 26 July 2019).

15. Oxley, J.; Shepherd, K. Need for welfare-related research on seized dogs. Vet. Rec. 2012, 171, 569-570. [CrossRef]

16. Collier, S. Breed-specific legislation and the pit bull terrier: Are the laws justified? J. Vet. Behav. Clin. Appl. Res. 2006, 1, 17-22. [CrossRef]

17. Cornelissen, J.M.R.; Hopster, H. Dog bites in the Netherlands: A study of victims, injuries, circumstances and aggressors to support evaluation of breed specific legislation. Vet. J. 2010, 186, 292-298. [CrossRef] [PubMed]

18. Mariti, C.; Sighieri, C.; Ciceroni, C. Italian breed-specific legislation on potentially dangerous dogs (2003): Assessment of its effects in the city of Florence. Dog Behav. 2015, 1, 25-31. (In Italy) [CrossRef]

19. Súilleabháin, P. Human hospitalisations due to dog bites in Ireland (1998-2013): Implications for current breed specific legislation. Vet. J. 2015, 204, 357-359. [CrossRef] [PubMed]

20. Position Statement on Breed-Specific Legislation. American Society for the Prevention of Cruelty to Animals. Available online: https:/www.aspca.org/about-us/aspca-policy-and-position-statements/position-statementbreed-specific-legislation (accessed on 30 July 2019).

21. Control of Dogs Regulations, 1998. Ireland. 1998. Available online: http://www.irishstatutebook.ie/eli/1998/ si/442/made/en/print (accessed on 26 July 2019).

22. Nilson, F.; Damsager, J.; Lauritsen, J.; Bonander, C. The effect of breed-specific dog legislation on hospital treated dog bites in Odense, Denmark-A time series intervention study. PLoS ONE 2018, 13, e0208393. [CrossRef] [PubMed]

23. Wisch, R.F. Overview of States that Prohibit Breed-Specific Legislation by State Law. Animal Legal \& Historical Center. Available online: https://www.animallaw.info/article/overview-states-prohibit-bsl (accessed on 26 July 2019).

24. American Pet Products Association. 2017-2018 APPA National Pet Owners Survey; American Pet Products Association Inc.: Greenwich, UK, 2018.

25. Mills, D.S.; Levine, E. The need for a co-ordinated scientific approach to the investigation of dog bite injuries. Vet. J. 2006, 172, 398-399. [CrossRef]

26. Scott, J.P.; Fuller, J.L. Genetics and the Social Behavior of the Dog; University of Chicago Press: Chicago, IL, USA, 1965. 
27. Webster, C.A.; Farnworth, M.J. Ability of the public to recognize dogs considered to be dangerous under the dangerous dogs act in the United Kingdom. J. Appl. Anim. Welf. Sci. 2019, 22, 240-254. [CrossRef]

28. Voith, V.L.; Ingram, E.; Mitsouras, K.; Irizarry, K. comparison of adoption agency breed identification and dna breed identification of dogs. J. Appl. Anim. Welf. Sci. 2009, 12, 253-262. [CrossRef]

29. Gunter, L.M.; Barber, R.T.; Wynne, C.D.L. A canine identity crisis: Genetic breed heritage testing of shelter dogs. PLoS ONE 2018, 13, e0202633. [CrossRef]

30. Olson, K.R.; Levy, J.K.; Norby, B.; Crandall, M.M.; Broadhurst, J.E.; Jacks, S.; Barton, R.C.; Zimmerman, M.S. Inconsistent identification of pit bull-type dogs by shelter staff. Vet. J. 2015, 206, 197-202. [CrossRef]

31. Hoffman, C.L.; Harrison, N.; Wolff, L.; Westgarth, C. is that dog a pit bull? A cross-country comparison of perceptions of shelter workers regarding breed identification. J. Appl. Anim. Welf. Sci. 2014, 17, 322-339. [CrossRef] [PubMed]

32. Lockwood, R.; Rindy, K. Are "Pit Bulls" different? An analysis of the Pit Bull Terrier controversy. Anthrozoos 1987, 1, 2-8. [CrossRef]

33. Arluke, A.; Cleary, D.; Patronek, G.; Bradley, J. Defaming rover: Error-based latent rhetoric in the medical literature on dog bites. J. Appl. Anim. Welf. Sci. 2018, 21, 211-223. [CrossRef] [PubMed]

34. Orritt, R.; Oxley, J. The History of Dog Bite Misinformation in UK News Media and Public Policy. In Proceedings of the ISAZ Conference 2015: Topics in Human-Animal Interactions: Significance in History and for the Future: Saratoga Springs, Saratoga, NY, USA, 7-9 July 2015; Available online: https://www.researchgate.net/publication/279960344_The_history_of_dog_bite_ misinformation_in_uk_news_media_and_public_policy (accessed on 26 July 2019).

35. Kikuchi, M.; Oxley, J.; Hogue, T.; Mills, D.S. The representation of aggressive behavior of dogs in the popular media in the UK and Japan. J. Vet. Behav. 2014, 9, e9. [CrossRef]

36. Kikuchi, M.; Oxley, J.A. The representation of human directed aggression in the popular media. In Dog Bites: A Multidisciplinary Perspective; Mills, D.S., Westgarth, C., Eds.; 5M Publishing: Sheffield, UK, 2017; pp. 57-68.

37. Podberscek, A.L. Dog on a tightrope: The position of the dog in british society as influenced by press reports on dog attacks (1988 to 1992). Anthrozoos 1994, 7, 232-241. [CrossRef]

38. Creedon, N.; Ó Súilleabháin, P.S. Dog bite injuries to humans and the use of breed-specific legislation: A comparison of bites from legislated and non-legislated dog breeds. Ir. Vet. J. 2017, 70, 23. [CrossRef]

39. Clarke, N.M.; Fraser, D. Animal control measures and their relationship to the reported incidence of dog bites in urban Canadian municipalities. Can. Vet. J. 2013, 54, 145-149.

40. Why Breed-Specific Legislation Is not the Answer. American Veterinary Medical Association. Available online: https://www.avma.org/public/Pages/Why-Breed-Specific-Legislation-is-not-the-Answer.aspx (accessed on 26 July 2019).

41. Dangerous Dogs. British Veterinary Association. Available online: https://www.bva.co.uk/News-campaignsand-policy/Policy/Companion-animals/Dangerous-dogs/ (accessed on 30 July 2019).

42. Dangerous Dogs. New Zealand Veterinary Association. Available online: https://www.nzva.org.nz/page/ policydangerousdogs (accessed on 30 July 2019).

43. RSPCA (Royal Society for the Prevention of Cruelty to Animals). Breed Specific Legislation-A Dog's Dinner. 2016. Available online: https://www.rspca.org.uk/webContent/staticImages/Downloads/BSL_Report.pdf (accessed on 26 July 2019).

44. Oxley, J.A.; Gaines, S. The welfare implications as a result of breed specific legislation in the UK. In Proceedings of the UFAW International Symposium, Surrey, UK, 27-29 June 2017.

45. 2018 Most Popular Dog Breeds-American Kennel Club. American Kennel Club. Available online: https://www.akc.org/most-popular-breeds/2018-full-list/ (accessed on 26 July 2019).

46. Agresti, A. Introduction to Categorical Data Analysis, 2nd ed.; John Wiley and Sons, Inc.: Hoboken, NJ, USA, 2002; Available online: https://mregresion.files.wordpress.com/2012/08/agresti-introduction-to-categoricaldata.pdf (accessed on 26 July 2019).

47. Loder, R.T.; Meixner, C. The demographics of dog bites due to K-9 (legal intervention) in the United States. J. Forensic Leg Med. 2019, 65, 9-14. [CrossRef]

48. Lyu, C.; Jewell, M.P.; Piron, J.; Ehnert, K.; Beeler, E.; Swanson, A.; Smith, V.L.; Kuo, T. Burden of bites by dogs and other animals in Los Angeles county, California, 2009-2011. Public Health Rep. 2016, 131, 800-808. [CrossRef] 
49. Matthias, J.; Templin, M.; Jordan, M.M.; Stanek, D. Cause, setting and ownership analysis of dog bites in bay county, Florida from 2009 to 2010. Zoonoses Public Health 2015, 62, 12115. [CrossRef]

50. Gilchrist, J.; Sacks, J.J.; Kresnow, M.-J. Dog bites: Still a problem? Inj. Prev. 2008, 14, 296-301. [CrossRef] [PubMed]

51. Holmquist, L.; Elixhauser, A. Emergency Department Visits and Inpatient Stays Involving Dog Bites, 2008: Statistical Brief \#101. Rockville, MD, USA, 2010. Available online: http://www.ncbi.nlm.nih.gov/pubmed/ 21413205 (accessed on 26 July 2019).

52. Stafford, K. Opinions of veterinarians regarding aggression in different breeds of dogs. N. Z. Vet. J. 1996, 44, 138-141. [CrossRef] [PubMed]

53. Gershman, K.A.; Sacks, J.J.; Wright, J.C. Which dogs bite? A case-control study of risk factors. Pediatrics 1994, 93, 913-917. [PubMed]

54. Oxley, J.A.; Christley, R.; Westgarth, C. Contexts and consequences of dog bite incidents. J. Vet. Behav. 2018, 23, 33-39. [CrossRef]

55. Schalamon, J.; Ainoedhofer, H.; Singer, G.; Petnehazy, T.; Mayr, J.; Kiss, K.; Höllwarth, M.E. Analysis of dog bites in children who are younger than 17 years. Pediatrics 2006, 117, e374-e379. [CrossRef]

56. Patrick, G.R.; O'Rourke, K.M. Dog and cat bites: Epidemiologic analyses suggest different prevention strategies. Public Health Rep. 1998, 113, 252-257.

57. American Veterinary Medical Association. Literature Review on the Welfare Implications of the Role of Breed in Dog Bite Risk and Prevention. Available online: https:/www.avma.org/KB/Resources/LiteratureReviews/ Documents/dog_bite_risk_and_prevention_bgnd.pdf (accessed on 26 July 2019).

58. Wake, A.; Minot, E.; Stafford, K.; Perry, P. A survey of adult victims of dog bites in New Zealand. N. Z. Vet. J. 2009, 57, 364-369. [CrossRef]

59. Borchelt, P.L. Aggressive behavior of dogs kept as companion animals: Classification and influence of sex, reproductive status and breed. Appl. Anim. Ethol. 1983, 10, 45-61. [CrossRef]

60. Svartberg, K.; Forkman, B. Personality traits in the domestic dog (Canis familiaris). Appl. Anim. Behav. Sci. 2002, 79, 133-155. [CrossRef]

61. Sacks, J.J.; Sinclair, L.; Gilchrist, J.; Golab, G.C.; Lockwood, R. Breeds of dogs involved in fatal human attacks in the United States between 1979 and 1998. J. Am. Vet. Med. Assoc. 2000, 217, 836-840. [CrossRef]

62. Dodman, N.H.; Patronek, G.J.; Dodman, V.J.; Zelin, M.L.; Cottam, N. Comparison of personality inventories of owners of dogs with and without behavior problems. Int. J. Appl. Res. Vet. Med. 2004, 2, 55. Available online: https://www.jarvm.com/articles/Vol2Iss1/DODMAN.htm (accessed on 29 July 2019).

63. Dodman, N.H.; Brown, D.C.; Serpell, J.A. Associations between owner personality and psychological status and the prevalence of canine behavior problems. PLoS ONE 2018, 13, e0192846. [CrossRef] [PubMed]

64. Todd, Z. Barriers to the adoption of humane dog training methods. J. Vet. Behav. 2018, 25, 28-34. [CrossRef]

65. Roshier, A.L.; McBride, E.A. Veterinarians' perceptions of behaviour support in small-animal practice. Vet. Rec. 2013, 172, 267. [CrossRef] [PubMed]

66. Kogan, L.R.; Hellyer, P.W.; Rishniw, M.; Schoenfeld-Tacher, R. Veterinary behavior: Assessment of veterinarians' training, experience, and comfort level with cases. J. Vet. Med. Educ. 2019, 46. [CrossRef]

67. Grigg, E.K.; Kogan, L.R.; van Haaften, K.; Kolus, C. Cat owners' perceptions of psychoactive medications, supplements and pheromones for the treatment of feline behavior problems. J. Feline Med. Surg. 2018, 21. [CrossRef]

68. Patronek, G.J.; Slater, M.; Marder, A. Use of a number-needed-to-ban calculation to illustrate limitations of breed-specific legislation in decreasing the risk of dog bite-related injury. J. Am. Vet. Med. Assoc. 2010, 237, 788-792. [CrossRef]

69. Patronek, G.J.; Sacks, J.J.; Delise, K.M.; Cleary, D.V.; Marder, A.R. Co-occurrence of potentially preventable factors in $256 \mathrm{dog}$ bite-related fatalities in the United States (2000-2009). J. Am. Vet. Med. Assoc. 2013, 243, 1726-1736. [CrossRef]

70. Delise, K.M. The Pit Bull Placebo: The Media, Myths and Politics of Canine Aggression; Anubis Publishing: Ramsey, NG, USA, 2007; Available online: https://www.shawpitbullrescue.com/app/download/.../The+Pit+ Bull+Placebo.pdf (accessed on 26 July 2019).

71. Gunter, L.M.; Barber, R.T.; Wynne, C.D.L. What's in a name? Effect of breed perceptions and labeling on attractiveness, adoptions and length of stay for pit-bull-type dogs. PLoS ONE 2016, 11, e0146857. [CrossRef] 
72. Bykowski, M.R.; Shakir, S.; Naran, S.; Smith, D.M.; Goldstein, J.A.; Grunwaldt, L.; Saladino, R.A.; Losee, J.E. Pediatric dog bite prevention: Are we barking up the wrong tree or just not barking loud enough? Pediatric Emerg. Care 2017, 35, 618-623. [CrossRef]

73. Pets by the Numbers. The Humane Society of the United States. Available online: https://www.humanesociety. org/resources/pets-numbers (accessed on 26 July 2019).

74. Sacks, J.J. Dog bite-related fatalities from 1979 through 1988. J. Am. Med. Assoc. 1989, 262, $1489-1492$. [CrossRef]

75. Reim, P. Breed-specific dog laws: Moving the united states away from an anti-pit bull mentality. J. Anim. Nat. Resour. 2018, 14, 159.

76. Patronek, G.J.; Bradley, J.; Cleary, D. Who is minding the bibliography? Daisy chaining, dropped leads, and other bad behavior using examples from the dog bite literature. J. Vet. Behav. 2016, 14, 17-19. [CrossRef]

77. Patronek, G.; Twining, H.; Arluke, A. Managing the stigma of outlaw breeds: A case study of Pit Bull owners. Soc. Anim. 2000, 8, 25-52. [CrossRef]

78. Strutzel, J. Pit Bull Ban a Waste of Taxpayer Dollars. Available online: https://www.platteinstitute.org/ Library/docLib/201007091_platte_chat_6-16-2010.pdf (accessed on 26 July 2019).

79. Mora, E.; Fonseca, G.M.; Navarro, P.; Castaño, A.; Lucena, J. Fatal dog attacks in Spain under a breed-specific legislation: A ten-year retrospective study. J. Vet. Behav. 2018, 25, 76-84. [CrossRef]

80. Raghavan, M.; Martens, P.J.; Chateau, D.; Burchill, C. Effectiveness of breed-specific legislation in decreasing the incidence of dog-bite injury hospitalisations in people in the Canadian province of Manitoba. Inj. Prev. 2013, 19, 177-183. [CrossRef]

81. Caffrey, N.; Rock, M.; Schmidtz, O.; Anderson, D.; Parkinson, M.; Checkley, S.L. Insights about the epidemiology of dog bites in a canadian city using a dog aggression scale and administrative data. Animals 2019, 9, 324. [CrossRef]

82. Lakestani, N.; Donaldson, M.L. Dog bite prevention: Effect of a short educational intervention for preschool children. PLoS ONE 2015, 10, e0134319. Available online: https://www.ncbi.nlm.nih.gov/pmc/articles/ PMC4542266/ (accessed on 15 October 2019). [CrossRef]

83. Meints, K.; Brelsford, V.; De Keuster, T. Teaching children and parents to understand dog signaling. Front. Vet. Sci. 2018, 5, 257. [CrossRef]

84. American Veterinary Medical Association. Task Force on Canine Aggression and Human-Canine Interactions. A community approach to dog bite prevention. J. Am. Vet. Med. Assoc. 2001, 218, 1732-1749. [CrossRef]

(C) 2019 by the authors. Licensee MDPI, Basel, Switzerland. This article is an open access article distributed under the terms and conditions of the Creative Commons Attribution (CC BY) license (http://creativecommons.org/licenses/by/4.0/). 